\title{
Food scares propagated by Media and their Impact on Consumer Perception of Food safety and consumption pattern
}

\author{
Kankona Dey¹, SubbaRao M. Gavaravarapu ${ }^{2 *}$, Paromita Banerjee ${ }^{3}$ and N. Balakrishna ${ }^{4}$
}

\begin{abstract}
Aim: Mass media exposure may have considerable impact on the eating habits of people. This study aimed to assess the impact of media portrayals of food safety issues on consumption pattern and perceptions of people. Media portrayals were compared with scientific rationality to judge if those are actual scares. Methods: Mixed methods approach was adopted. Google trends were used to shortlist the top 5 food scares. A closed-ended, pre-tested, self-administered questionnaire was used to assess the exposure to food safety news, perspective and consumption of the foods after media portrayals of food scares of 96 adults (25-45years) recruited from 5 zones of Kolkata, India. In-depth interviews with stakeholders around the country were conducted to bring out the scientific rationale behind those food scares. Results: The top 5 media propagated food scares were-2minute noodle controversy; artificial ripening of fruits and vegetables, pesticide residues in fruits and vegetables; milk adulteration and hormonal injections to fruits and milch cattle. Newspapers were the major source of information for $95.8 \%$ of the respondents followed by television for $92.7 \%$ respondents. While $50 \%$ respondents considered newspapers as the most credible source. Irrespective of literacy status none of the respondents changed their consumption patterns after food scare exposure. The in-depth interviews with stakeholders revealed that media-hyped food safety issues often lack scientific evidence. Conclusion: Although people were scared after media portrayal of food scares, they did not change consumption patterns. According to the scientists the media claims lacked scientific rationality and should not be considered as actual scares.
\end{abstract}

Keywords: Food scare, food safety, risk perception, media exposure, risk amplification

\section{Introduction}

There is no lexical definition of the term "food scare", it is generally associated with spiralling public anxiety over food safety incidents and escalating media attention that supplements such events. "Food scare" is the term given to the incident when there is a significant decrease in demand caused by surge of negative media information about any product, even though the truth behind the risk is not proved (Agricultural and Resource Economics Review, 2009). The processes by which certain hazards and events that experts assess as relatively low in risk become a focus of concern and socio-political activity in a society is termed as Risk Amplification. Highly publicized food safety events can affect consumer perceptions and lead

1 Independent Consultant Nutritionist, Kolkata, India

2,3 Media, Communication, and Extension Group, Extension and Training Division. National Institute of Nutrition, Indian Council of Medical Research, Hyderabad, Telangana, India

4 Department of Biostatistics, National Institute of Nutrition, Indian Council of Medical Research, Hyderabad, Telangana, India to change in their food purchasing and consumption pattern, resulting in a fall in the sales. Risk perceptions represent a person's views about the risk inherent in a situation and are more often influenced by psychological factors including interpretation of product properties and risks than the physical properties of products themselves. The concerns of consumers about food risks have increased in the last decade, while the trust in government and industry to control and monitor food risks has been eroded. The controversies and issues relating to foodstuffs have received a high level of newsmedia attention in recent years. Consumers of today have greater access to such information than ever before-through television, newspapers, journals, radio and the internet (Kasperson, 1988). In Western countries, controversies related to genetically-modified (GM) foods, advent of bovine spongiform encephalopathy (BSE) or 'mad cow disease' in cattle and the cloning of livestock, pesticide residues in food and contamination of drinking water etc created huge scare and loss of billions of dollars in the recent past. Recent research indicates that most respondents in nineteen of thirty-four countries feel their food is less safe than 10 years ago. Individual and societal perceptions of food-related health risks are multidimensional and complex and are affected 
by social, political, psychological, and economic factors (Dosman, 2001). Media-fuelled food scares are often linked to consumers' food anxieties. However, studies of food consumption have failed to answer fully how food-scare reports add to consumers' anxieties. The aim of this paper was to review the major food scares that have occurred in the preceding years of the study and investigate perceptions and behavioural changes subsequently implemented by the people. The study also aimed to understand the connect and disconnect of media portrayal with people's perception and scientific rationality of these food scares. It was anticipated that the main contribution of this paper will be to provide a unique insight into the "food scares" prevalent and present a critical analysis relating to the scientific experts' responses to the rationality of these food scares.

\section{Objectives}

1. To identify the recent food scares propagated by media.

2. To assess the impact of these media propagated food scares on the food purchase and consumption of urban consumers.

3. To triangulate the information depicted in the media concomitant consumer perceptions about these food safety issues with the opinions of the stakeholders: the scientists and the regulators.

\section{Methodology}

The study was approved by Institutional Ethics Committee (IEC). It employed a mixed method approach that included qualitative and quantitative phases to address multiple objectives.

Study Design The study consisted of three distinct phases.

(i) In the first phase, empirical information from an online database, Google Trends was used to identify the top 5 food scares in the year 2016.

(ii) In the second phase, in order to understand the impact of these media propagated food scares on the food consumption and food behaviours of consumers, a cross-sectional study was conducted using a quantitative precoded, pre-tested, self-administered questionnaire.

(iii) In the last phase of the study in-depth interviews were conducted with scientists and food regulators to understand their views on the media propagated food scares.

Study Location The quantitative part of the study was conducted in Kolkata, a metro city in the Eastern part of India. However, the qualitative part of the study consisting of indepth interviews, experts from different parts of the country were included. Some interviews were conducted at mutually convenient places and the others were conducted telephonically.

Subjects In order to assess the impact of these food scares on consumption pattern, 96 adults (25-45 years) belonging to middle- and highincome groups were included, assuming the prevalence of outcome as $50 \%$ with $95 \%$ confidence interval and 10\% absolute precision. Subjects were recruited using stratified random sampling technique from 5 geographical zones (East, West, North, South and Central) of Kolkata. Income grouping was done based on "Socioeconomic Status Scale of Kuppuswamy" (Urban, 1976).

In-depth interviews were conducted with 4 experts- food scientist, regulator, implementer, and a nutritionist who were engaged in food policy, food safety, dietetics and nutrition respectively.

Inclusion criteria i) Individuals who were exposed to the media related food scares stated in the questionnaire.

ii) Individuals responsible for choosing foods for their family by the way of purchasing, procuring and/ or preparing.

iii) Individuals willing to take part in this study.

\section{Systematic study protocol}

Identification of top 5 food scaresthe recent food scares propagated by media (newspapers) were identified by using the keywords in Google trends, a versatile search engine. Google metrics helped in tracking the most read or downloaded news items on food safety and identified the top 5 recent food scares.

(ii) Assessing consumer perception and behaviourA pre-coded, closed-ended, pre-tested questionnaire was used. It consisted of 108 closed-ended questions including socio-demographic detail, respondent's definition of food scare, reliability on media-induced food scares, how they tackled the information, perceptions about each of the scares, any alteration of behaviour and consumption. 
Before administering the questionnaire, written informed consent was obtained from each of the participants.

(iii) Scientific views about the food scares: A theme guide consisting of 6 broad themes was prepared around which the discussions would focus and a few probes that helped the moderator to trigger discussion and ensure all the key points are covered. In-depth interviews were conducted either in person or telephonically. The respondents were affiliated to recognized bodies in India like Food Safety Standards Authority of India (FSSAI), Nutrition Society of India (NSI) and Indian Dietetic Association (IDA). The purpose of the study was explained to them and consent was taken. Each interview session lasted for about 45 minutes. The discussions were recorded and transcript soon after.

Data Analysis The quantitative data from 96 respondents were entered into a Microsoft Excel sheet and statistical analysis was carried out using SPSS version 21.0.0 (Software Package for Statistical Analysis). Descriptive statistics was conducted to determine the sociodemographic characteristic, McNemar test was conducted to check the significant difference in the frequency of consumption and purchase pattern before and after the controversy of each scare. Pearson's chisquare test was conducted to assess the association between variables.

\section{Results}

(i) Top 5 media propagated food scares Based on metrics of Google Trends the top 5 media propagated food scares were controversy related to a popular brand of 2-minute instant noodles; artificial ripening of fruits \& vegetables, pesticide residues in fruits and vegetables; milk adulteration and hormonal injections to fruits and milch cattle.

(ii) Effect of media food scare on consumer perception and consumption pattern

Socio-demographic profile of the respondents the total number of respondents covered in this study was 96, with 43 individuals from middle-income group and 53 individuals from high-income group. (Insert Table1 here)

Respondent's exposure to food scares and perception Most of the respondents were exposed to all the identified food safety issues. The highest frequency of exposure being about 2-minute noodles controversy (99\%), however, only 69.5\% believed it to be true. It was followed by scare of pesticides $(97.9 \%)$ and artificial ripening of fruits \& vegetables $(92.6 \%)$, which all the respondents believed as a valid scare. Exposure to scare of milk adulteration was $86.35 \%$ and was believed by $66.3 \%$ respondents. Scare of hormonal injections was known to $80 \%$ respondents while considered true by $74.7 \%$. (Insert Figure1 here)

Source of information of the food scaresAll the information was sourced from multiple media. However, majority of the respondents (95.8\%) sourced the information regarding 2-minute noodles scare from traditional media like newspaper and $92.7 \%$ sourced from television. Scare of hormonal injection were sourced from both newspapers and television by $50 \%$ respondents. The scare about artificial ripening was sourced by $72.9 \%$ respondents through social networks. The scare of pesticide residues in fruits, vegetables were sourced by most respondents (99\%) through scientific journals, magazines followed by television and social networks. Most respondents (69.8) \% came across scare of milk adulteration through newspapers and television (Insert Figure 2 here)

Credibility of sources of information When the respondents were asked about their perceptions of credibility about the above-mentioned sources of information, a mixed response was obtained. Newspapers received the highest amount of trust and considered to be very credible by $50 \%$ respondents, followed by television which was credible by $37.5 \%$. While most respondents considered word of mouth; information from friends and peers, social media as least credible. There was a difference of opinion about the credibility of information available on web searches, while $32.3 \%$ considered it to be very credible, $21.9 \%$ respondents believed the information were incorrect and noncredible. When asked what they would consider as authenticated information on food safety, $45.8 \%$ respondents said that news about such scares can be more credible if a scientific institution or the FSSAI $(39.6 \%)$ came out with clarifications on food safety issues from time to time. (Insert Figure 3 here)

Change in frequency of consumption after exposure to scare About $50 \%$ of the respondents stated that they considered the 2-minute instant noodles, hormonal injection and artificial ripening to be unsafe only after being exposed to the media scare. Consumption pattern had undergone a significant change for the noodles while the natural foods like fruits, vegetables, milk did not record any significant change even after exposure to the scare. Most respondents 
were consuming the 2-minute noodles before the controversy broke out in a consumption pattern of - every day $(4.2 \%)$, often $(16.7 \%)$, sometimes $(32.3 \%)$ and rarely $(27.1 \%)$. All these respondents had stopped consuming the controversial brand of noodles taking into consideration its ban as well as personal perceptions (either of the 2 reasons). When that brand of noodles was relaunched, 49\% respondents resumed their purchasing and consumption pattern. The respondents with education level below $12^{\text {th }}$ grade had a lesser change $(55.6 \%)$ in their consumption pattern as compared to the respondents above graduate level $(84.6 \%)$ in case of 2-minute noodles. All respondents were consuming big-sized (hybrid) fruits, normal fruits, and milk before exposure to the food scare, about $52.1 \%$ respondents said that though they considered pesticide residues in fruits and vegetables to be a major food scare but followed their usual consumption pattern even after exposure to the news. These scares showed no association between change in consumption pattern and literacy status. (Insert Figure 4 here)

\section{(iii) Scientific rationale behind media propagated food scare:}

The key findings from the in-depth interviews with scientists, regulators and nutritionists are as follows.

The 2 minute instant noodles brand The media scare propagated for 2-minute noodles was due to presence of impermissible amount of lead and Monosodium Glutamate (MSG), which resulted in ban of 2-minute noodles by the Indian government on the grounds of being dangerously harmful for consumption. The ban had been removed after 4 months by Bombay High court after valid proof.When interviewed, the experts were of the opinion that the controversy related to the popular brand of 2-minute instant noodles was a case of food label violation, since there is no test available to detect "added MSG". Also, the levels of lead were considered to be within permissible limits by the experts. The Food safety Scientist said, "There is no method to detect 'added MSG'. So the false positive was because of the methodology used as you cannot detect MSG, you can only detect glutamate, we get more than 95\% glutamate naturally from foods itself, for example tomatoes. If somebody is analysing tastemaker separately, there may be chances that lead maybe more than $2.5 \mathrm{ppm}$ (but the regulation is for the entire product). It was misinterpretation of analysis."

"We cannot say 'it was proved in lab' because the lab was found to be faulty. 'Proved' means

the tests have been done properly using validated methods, proper lead-free testing methods and a lab which is accredited by National Accreditation Board. If any of these is not met, then it should not be considered a proof/ any kind of evidence" said the Nutrition Scientist.

Hormonal injections the media propagated scare was that steroids and hormones like oxytocin (steroid hormone) are being injected into fruits and vegetables to make them bigger and shinier. The media reports pointed that these fruits and vegetables injected with hormones pose a high risk to humans if consumed. The experts had more or less turned down the concept of hormonal injections as being scientifically invalid. Instead they have focussed on the value and need for hybridization.

"If media are telling us about oxytocin being given to plants, then it's not scientifically valid as an animal hormone cannot be injected to the plant, and even if injected will not have any such effects" said theFood safety scientist.

Artificial ripening of fruits the scare propagatedwasthat calcium carbide powder was being used on fruits externally for ripening the fruits artificially. This compound is hazardous and creates a risk for consumers. According to the experts, all fruits cannot be artificially ripened. The levels of using calcium carbide are within the permissible limits.

"I don't think artificial ripening itself is unsafe,
because the levels that they use for ripening
doesn't cause any harm, but carbide itself is a
banned carcinogen" Nutritionist

"Internationally there are no documentation of this particular chemical causing any particular disease. Washing, I think, will remove most of the powder" Nutrition Scientist.

Milk adulteration the media propagated that milch cattle are injected with oxytocin injection (female hormone which helps in breast milk secretion) for artificially boosting milk production, which is hazardous for human consumption. According to the experts, this media propagated news is just a scare. This doesn't pose any potential threat.

"Packaged milk follows regulations and is not hazardous. That is what I have been telling my patients; the package and seal from an authority would have an adulterant which is permissible. But the media hype has made it a big issue" Nutritionist.

"It is clearly shown in National Institute of Nutrition's research that oxytocin doesn't have any risk. We boil the milk; some amount of oxytocin remains, but when you consume it, a 
bit is digested in the GIT. Therefore, oral consumption of oxytocin doesn't cause any harm." -Nutrition Scientist

Pesticide residues-Pesticides are indiscriminately used by farmers and the residues of the media propagates that these pesticides pose potential threat to human health. According to the experts, the pesticides are allowed in the market after a proper risk assessment within the specified permissible limits. "They have to be used as per Good Agricultural Practices. So as per the survey reports, hardly 2-3\% of fruits and vegetables are having pesticide residues more than Maximum Residual Limit. There is All India Co-ordinated project on pesticide residues on the net, data is available. Most pesticides are washed off." - Food safety scientist

"Even before a pesticide is released in the market, adequate amount of toxicological studies are done for 'Risk Assessment' to understand what the potential hazards of the pesticide are and prescribe the ADI/ MRL. Even the International Agency of Cancer also doesn't say that pesticide as one of the main causes of cancer."- Nutrition Scientist

\section{Discussion}

This study used a mixed method approach to assess the impact of media portrayed food scares on the consumption pattern and perceptions of the adult participants and the perspective of the scientists and regulators about the truth behind such scares. Although, there are studies in India that assessed the extent of nutrition-related news reports in relation to the other reports in Indian newspapers (Maheshwar, 2011; Gupta, 2010). There are hardly any studies that linked the media portrayed scare and scientific truth; nor have they compared and assessed how media impacts the people's perception. Only limited studies have been carried out to understand the food safety knowledge, attitudes and practices (SubbaRao, 2007, 2009), but these too did not consider the media portrayal of food risks. Earlier studies in the West revealed preference of traditional channels of communication, despite a strong preference for social media in their private lives (Fried, 2011).

Our study findings revealed newspapers were the most credible (50\%) form of mass media which plays a significant role in perception of food safety. Although newspapers are considered to be a credible source of information, studies in India have revealed that newspaper reports lack consistency in presenting nutrition research results to the readers, disproportionately highlight, overemphasize and run contrary to health recommendations instead of translating truths from researches/scientists to consumers (Maheswar, 2014). A study in Europe reported that people are generally doubtful of all the 3 media channels but do rate newspapers with the highest credibility, followed by online news and television news, respectively (Kiousis S, 2009). In our study, television was rated to be $12.5 \%$ less credible than newspapers, which is supported by study which stated that television claims to report reality but largely creates its own reality. It dramatizes and exaggerates the importance of events. Reliability in food risk information may be an important determinant of public reactions to that information. Our findings revealed that people were scared after being exposed to the food scares by media, especially about pesticide residues in fruits and vegetables which can be supported by a study which concluded that risk is perceived more when it is felt or heard rather than being known (Sweta et al, 2014). A study in Bologna asserted "no news is good news" and concluded inclusion of time-varying parameters in-demand models enables the capturing of the impact of food safety information and provides better short-term forecasts (Mazzochhi, 2005). Our study also found out that only in case of 2minute noodles related scare, literacy status had an association with the change in consumption pattern $(84.6 \%)$ however, reported no association between the two in other cases. This is supported by a study which revealed a gap between perception and evidence is larger among consumers with lower literacy status.

A study utilized experimental economics to measure consumer's willingness to pay (WTP) for a hamburger and their concern for food safety after viewing a beef advertisement and a video regarding mad cow disease. A stark difference was observed in WTP between the group that viewed both videos and those who didn't view the BSE video provided clear evidence that generic advertising for a product can be a useful tool in offsetting negative messages by the media (Messer, 2015). There was clear cut difference seen in the changes in consumption pattern between convenience foods and basic foods. While respondents were not ready to consume the particular brand 2-minute instant noodle during the time of controversy but the other foods such as fruits and vegetables/milk which also had pesticide/ hormonal controversy were consumed. This might be because respondents did not have any other option to opt for in place of those basic foods like food crops, fruits and vegetables and milk. Respondents explained this behaviour pattern to be a cause of "no other 
alternative/substitute". They have accepted this as a matter of life (Sweta, 2014).

\section{Strengths and Limitations}

The strengths of the study include being the first of its kind, in India as per our knowledge. The consent was taken for participation of the respondents as well as administration of the questionnaire in an interview mode. Moreover, multiple points of views were captured due to the mixed methods approach (quantitative and qualitative). The number of participants was restricted and represented a similar geographic and cultural background, hence the generalisability is limited.

\section{Conclusion}

In our contemporary society, many food safety risks which are invisible are brought to the attention of the public through mass media portrayal, where the widening gap between producers and consumers in the developed world increases the need for consumer trust in the food supply. A study conducted showed the importance of newsworthiness where media actors (people involved in different types of media) construct stories which are liable for food risk amplification creating consumer anxiety about the safety of the food system. It is important for the food regulators and public health professionals to be aware of this anxiety when presenting information about a food safety concerns that they can target their message for the betterment to decrease their levels of consumer anxiety. An improved understanding of food safety perceptions and attitudes will enable policymakers and agricultural industries to better anticipate consumers changing consumption behaviour, if a breach of food safety event occurs. It is a necessity to have a streamlined risk communication through stakeholders. For example, consistent information from food regulators about 2-minute noodles and the situation controlled by the Indian Government resulted in a drop-in consumption pattern. Hence, this study highlights the importance of such necessary efforts. Science journalism is expected to disseminate scientific knowledge and making this knowledge widely accessible for audiences outside the scientific community. It is essential that consumer interests are put as a foremost concern, and that the relevant organisation counters the misleading information with clear and accurate content. There is a need for the food industry and the government authorities to improvise on their communication skills for a better understanding of food science and the scientific validity behind any food safety incident.

The inter-relationship between the media, the food industry and the consumer is probably at its lowest point. as we progress towards sustainable development goals. Most television stations and newspapers are now privately owned and therefore have they're own financial and other added interests. To mark their presence in the market, they need to please both shareholders and audiences by providing the kind of information that mass audiences expect and easily sway the public, particularly by creating fear, even in the absence of information or proper analysis. The media itself sets the stage for the public's response by choosing which information to present and perhaps more importantly, how to present it. One criticism that is often levelled at the media is that it is biased against positive news stories and seems to focus on negative news stories favouring 'sound bites' with simple conclusions. Lower-quality journalism and less coverage of complex issues, driven by competitive pressures have forced media companies to cut back on reporting and editorial staff in areas that do not attract many readers or viewers (McCluskey and Swinnen, 2011). In a study it was concluded that the mass media, in their quest for sensationalizing news, ended up being tagged as unreliable sources of information. Scares are serious issues that have a significant impact in terms of consumer behaviour, economics and politics. Nutrition-related information portrayed by media, is often overemphasized and could confuse readers. According to a study by Maheshwar and Rao, appearance of such kind of information is about $4 \%$ which cannot be ruled out as insignificant since media have potential influence on readers

The process of conveying scientific information through the media has been linked to a "communications chain", which has the scientist on one end and the journalist who delivers the information on the other end. In between are several key players who may influence the end result, including editors, public affairs professionals, special-interest groups, and representatives of the food, pharmaceutical or supplement industries (Ruth, 2001). In our study, the respondents felt any information by a scientific institute $(45.8 \%)$ as a method of food safety authentication was most credible whereas scientist spokesperson $(7.3 \%)$ was kept to a minimum. But in the Indian context, no Institute has been found that have helped in the Risk Communication. Hartz and Chappell claimed in 1997 that "the distance between science and 
journalism threatens America's future" based on surveys of US scientists and journalists, pointing to the political and economic implications of the science-media interface. Moreover, they noted that among the factors obstructing communication, scientists and journalists being strangers to each other, not being able to understand each other's language, and were driven by different agendas. Most people were willing to invest their trust in government bodies and health professionals to provide accurate information about food risks, as well as trusting their own judgement. This is supported by a study done in Australia (Lupton, 2005).

The future recommendations and directions include further studies to be done with different groups of people and more information is required to formulate a Risk Communication Strategy between the stakeholders and the public.

\section{References}

Agricultural and Resource Economics Review 38/3. (2009). Northeastern Agricultural and Resource Economics Association, 295- 310.

Dosman et al. (2001). Socioeconomic Determinants of Health-and Food SafetyRelated Risk Perceptions, Risk Analysis, 21 (2): 307-318

Fried J, Vercic. (2011). “Media Preferences of Digital Natives' Internal Communication: A Pilot Study", Public Relations Review, 37 (1): 84-86

Gupta and Sinha. (2010). "Health Coverage in Mass media: A Content Analysis", J Communication, 1(1): 19-25

Hartz J and Chappell R. (1997). “Worlds Apart: How the Distance Between Science and Journalism Threatens America's Future (First Amendment Center, Nashville, TN)"

Kasperson et al. (1988). The Social Amplification of Risk: A Conceptual Framework, Risk Analysis, 8 (2):177-187

Kiousis S. (2001). "Public Trust or Mistrust? Perceptions of Media Credibility in the Information Age", Mass Communication and Society, 4(4):381-403.

Lupton DA. (2005). "Lay discourses and beliefs related to food risks:an Australian perspective", Sociology of Health and Illness, 27(4):

448-467

Maheswar and SubbaRao et al. (2014). "The Quality of Nutrition Research Reporting by Leading daily Newspapers in India", Journal of Media and Communication Studies, 6(6): 92-98

Marzocchi M. (2005). "No News Is Good News: Stochastic Parameters versus Media Coverage Indices in Demand Models after Food Scares"

McCluskey and Swinnen. (2004). "Political economy of the Media and Consumer Perceptions on Biotechnology", Amer J. Agr Econ,86(5):1230-1237

McCluskey and Swinnen. (2011). "The media and food-risk perceptions", Science and Society series on Food and Science, European Molecular Biology Organization Report, 12(7): 624-629

Messer et al. (2005). Can Generic Advertising Alleviate Consumer Concerns Over Food Scares?, Applied Economics, Cornell University, Food and Brand Lab, 1-15

Ruth M.W. Yeung, Joe Morris. (2001). "Food safety risk: Consumer perception and purchase behaviour", British Food Journal, 103 (3):170 - 187

SubbaRao GM, Sudarshan R.V., et al. (2007). "Food safety knowledge, attitudes and practices of mothers - findings from focus group studies in south India", Appetite,49:441 -449 .

SubbaRao GM, Sudershan R.V., Rao et al. (2009). "Focus group studies on food safety knowledge, perceptions and practices of school going adolescent girls in South India", Journal of nutrition education and behaviour, 41(5):340-346.

Sweta et al. (2014). "Food Risk Perceptions of Women in Rural and Urban Households: A Study done in India", European Journal of Nutrition and Food Safety, 4(4): 380- 391

Taylor M et al. (2016). "Changes in U.S. consumer response to food safety recalls in the shadow of a BSE scare", Food Policy, 62:56-64 


\begin{tabular}{|c|c|c|c|}
\hline $\begin{array}{l}\text { S1 } \\
\text { No. }\end{array}$ & Indicator & Variables & $\begin{array}{c}\text { Total } \\
(\mathrm{N}=96) \\
\mathrm{n}(\%)\end{array}$ \\
\hline \multirow{2}{*}{1.} & \multirow{2}{*}{ Sex } & Male & $41(42.7)$ \\
\hline & & Female & $55(57.3)$ \\
\hline \multirow[t]{4}{*}{2.} & \multirow[t]{4}{*}{ Age } & $25-30$ & $41(42.7)$ \\
\hline & & $30-35$ & $19(19.8)$ \\
\hline & & $35-40$ & $5(5.2)$ \\
\hline & & $40-45$ & $31(32.3)$ \\
\hline \multirow[t]{3}{*}{3.} & \multirow{3}{*}{$\begin{array}{l}\text { Marital } \\
\text { status }\end{array}$} & Single & $35(36.5)$ \\
\hline & & Married & $60(62.5)$ \\
\hline & & Divorced & $1(1.0)$ \\
\hline \multirow[t]{4}{*}{4.} & \multirow{4}{*}{$\begin{array}{c}\text { Literacy } \\
\text { status }\end{array}$} & Secondary & $7(7.3)$ \\
\hline & & $\begin{array}{c}\text { Intermediat } \\
\mathrm{e}\end{array}$ & $11(11.5)$ \\
\hline & & Graduate & $40(41.7)$ \\
\hline & & $\begin{array}{c}\text { Postgraduat } \\
\mathrm{e}\end{array}$ & $38(39.6)$ \\
\hline \multirow[t]{5}{*}{5.} & \multirow{5}{*}{$\begin{array}{c}\text { Occupatio } \\
n\end{array}$} & Housewife & $16(16.7)$ \\
\hline & & Student & $6(6.3)$ \\
\hline & & $\begin{array}{c}\text { Private } \\
\text { employee }\end{array}$ & 46 (47.9) \\
\hline & & $\begin{array}{l}\text { Governmen } \\
\text { t employee }\end{array}$ & 14 (14.6) \\
\hline & & Business & $14(14.6)$ \\
\hline \multirow[t]{3}{*}{6.} & \multirow{3}{*}{$\begin{array}{l}\text { Family } \\
\text { type }\end{array}$} & Joint & $39(40.6)$ \\
\hline & & Nuclear & $51(53.1)$ \\
\hline & & Extended & $6(6.3)$ \\
\hline \multirow[t]{3}{*}{7.} & \multirow[t]{3}{*}{$\begin{array}{l}\text { Family } \\
\text { safety }\end{array}$} & $\begin{array}{l}\text { Purchasing } \\
\text { food }\end{array}$ & $42(43.8)$ \\
\hline & & $\begin{array}{l}\text { Preparing } \\
\text { food }\end{array}$ & $23(24.0)$ \\
\hline & & Both & $31(32.3)$ \\
\hline \multirow[t]{4}{*}{8.} & \multirow{4}{*}{$\begin{array}{l}\text { Family } \\
\text { monthly } \\
\text { income }\end{array}$} & Middle & $19(19.8)$ \\
\hline & & $\begin{array}{l}\text { Upper } \\
\text { middle }\end{array}$ & $24(25.0)$ \\
\hline & & High & $32(33.3)$ \\
\hline & & Upper high & $21(21.9)$ \\
\hline \multirow[t]{2}{*}{9.} & \multirow{2}{*}{$\begin{array}{l}\text { Type of } \\
\text { house }\end{array}$} & Own & $76(79.2)$ \\
\hline & & Rented & $20(20.8)$ \\
\hline \multirow[t]{2}{*}{10.} & \multirow[b]{2}{*}{$\begin{array}{c}\text { Number } \\
\text { of } \\
\text { bedrooms } \\
\text { in the } \\
\text { house }\end{array}$} & Two & $64(66.7)$ \\
\hline & & $\begin{array}{c}\text { Three or } \\
\text { more }\end{array}$ & $32(33.3)$ \\
\hline
\end{tabular}

Table 1: Socio-demographic details of the respondents
List of figures



Figure 1: Media sources from which respondents obtained information about different food scares



Figure 2: Perceived credibility of sources of Information among the respondents



Figure 3: Considering food as unsafe before and after exposure to media food scare

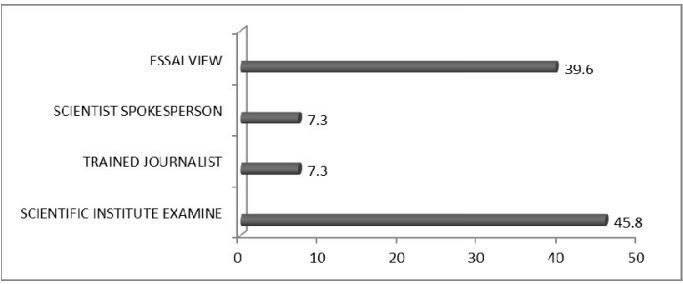

Figure 4: Most credible sources that could give clarity on food safety issues according to the respondents 